\section{New Unstable Cosmic Ray Particles}

IN an important paper (Phys. Rev., 78, $290 ; 1950$ ), Prof. Carl Anderson, of the Califormia Institute of Technology, together with four colleagues, A. J. Seriff, R. B. Leighton, C. Hsiao and E. W. Cowan, presents conclusive evidence for the existence of two new unstable cosmic ray particles. Using a counter-controlled cloud chamber in a magnetic field of 6,500 gauss, 3,000 photographs of penetrating events were made near sea-level and 8,000 at an altitude of $3,700 \mathrm{~m}$. In all, 34 'forked tracks' were found, similar to the two photographed in Manchester by Rochester and Butler (Nature, 160, 855; 1947), and interpreted by them as representing the decay of neutral and charged unstable particles of a new type and of mass around 900 electron masses. Of Anderson's 34 forked tracks, 28 were due to the decay of neutral particles and 6 to the decay of charged particles. The mass of the unstable particles was estimated as probably between 250 and 400 electron masses greater than the sum of the masses of the decay products. It was further suggested that perhaps all the particles may not have the same mass. Evidence is provided that at least some of the decay products are nuclear interactive and are thus most probably $\pi$-mesons, or conceivably protons.

From the distribution of decay processes across the chamber, the life-time of the neutral particle was determined as $(3 \pm 2) \times 10^{-10}$ sec., and some evidence was obtained which indicated a considerably shorter life for the charged particles. These figures show that Rochester's and Butler's crude estimate of life-time, based on only two examples, was too high by a factor of over a hundred. These new particles are certainly so massive as to put their artificial production in the laboratory at least a fow years in the future. Thus the accurate determination of the masses and life-times of the particles, and of their possible relation with other reported examples of very heavy mesons decaying in a different manner or not decaying at all (Brown, et al., Nature, 163, 87 ; 1949. Harding, Phil. Mag., 41, 405. LeprinceRinguet, Rev. Mod. Phys., 21, 42; 1949. Butler, Barker and Rosser, Phys. Soc., 63, 145; 1950), will remain a major task of cosmic ray research in the next few years.

\section{National Collection of Industrial Bacteria}

A national collection of industrial bacteria was begun at the Chemical Research Laboratory (Department of Scientific and Industrial Research) early this year. It took over the non-pathogenic cultures held by the National Collection of Type Cultures at Colindale, and now houses some three hundred and fifty types. This number is expected to increase considerably as the Collection becomes more representative of the needs of industry. The Laboratory will maintain any organism which has ceased to be of interest but which may be wanted later. It frequently happens that a particular organism is destroyed when it has fulfilled its temporary purpose and yet may be required in the future at short notice. The Laboratory will also maintain any organism which for one reason or another should be duplicated. Most of the nonpathogenic bacteria supplied up to now by Colindale can be obtained from the Chemical Research Laboratory, and the Laboratory will try to procure any type of non-pathogenic culture which it does not hold itself. In time, it is hoped that the collection will become comprehensive, and gaps are being filled by obtaining cultures from other laboratories in
Great Britain and abroad. Particular emphasis will be given to assay organisms. Cultures held by the Collection will be included in the United Kingdom List of Species to be published in 1951. Inquiries should be addressed to the Director, Chemical Research Laboratory, Teddington, Middlesex.

\section{The Brotherton Collection, University of Leeds}

THE fourteenth annual report of the Committee for the Brotherton Collection of the University of Leeds, covering the session 1948-49 (pp. 9; Leeds: the University, 1950), records the contents of the Collection on June 30,1949 , as 22,887 books, 15,642 pamphlets, 477 manuscripts, 4,105 deeds, 31,251 letters and 25 maps. The first public exhibition of the session was arranged in connexion with a visit of delegates to the International Geological Congress held in London, while another exhibition, on the history of printing, illustrated lectures at the Leeds College of Art and the Department of Printing of the Leeds College of Technology. Visitors during the session numbered 850, including twenty-eight organised parties. A list of acquisitions is given in the report.

\section{Newfoundland Biological Station for Fishery Research}

Fisheries research in Newfoundland, which was formerly the responsibility of the Newfoundland Government Laboratory, is now being carried on under the Fisheries Research Board of Canada. The name of the Laboratory has been changed to that of the Newfoundland Biological Station. This Station will in future carry on work in marine biology and hydrography only. With Bulletin No. 18 ("Lobster Investigations in Newfoundland, 1938-1941", by W. Templeman and S. N. Tibbo), bulletins of the Newfoundland Government Laboratory will come to an end, and publication in future will be through the Journal, bulletins and other publication channels of the Fisheries Research Board of Canada. The new address of the Laboratory will be the Newfoundland Biological Station, St. John's, Newfoundland. We wish the Station every success under the new regime.

\section{Conference on Civil Engineering Problems in the \\ Colonies}

A CONFEREnce on civil engineering problems in Colonial territories will be held at the Institution of Civil Engineers, Great George Street, Westminster, London, S.W.1, during July 3-7. This is the second such conference to be organised by the Institution, and, following the successful one held at Oxford in 1948 , it has been decided to make it a biennial event. These meetings are intended primarily to meet the needs of civil engineers in the Colonial engineering service. The programme consists of technical sessions, when papers are presented and discussed; visits to engineering works ; and a reception at the Institution on July 7. One of the technical sessions is being devoted to "Engineering Research and the Colonial Engineer", when short lectures from the directors of the Road Research Laboratory, Forest Products Research Laboratory, Hydraulies Research Organisation, Building Research Station, and the Water Pollution Research Laboratory will be given. It is intended to publish, in due course, the proceedings of the conference, which will contain all the papers and lectures presented, together with the discussions thereon. Attendance at the conference is not limited to members of the Institution of Civil Engineers, and non-members desirous of attending should apply to the secretary of the Institution. 